\title{
Partial Inferior Pubectomy in the Delayed Repair of Pelvic Fracture Urethral Injury: Adopting a Bone-nibbling Technique
}

\author{
Ikenna Ifeanyi Nnabugwu, ${ }^{1,2}$ Fredrick Obiefuna Ugwumba, ${ }^{1,2}$ Anthony Alex Ilukwe ${ }^{2}$
}

${ }^{1}$ Department of Surgery, College of Medicine, University of Nigeria, Enugu Campus, Enugu, Nigeria

${ }^{2}$ Department of Surgery, University of Nigeria Teaching Hospital, Ituku-Ozalla, Enugu, Nigeria

Correspondence to: Dr. Ikenna Ifeanyi Nnabugwu; email: ikenna.nnabugwu@unn.edu.ng

Received: 08 April 2020; Revised: 10 June 2020; Accepted: 19 June 2020; Available online: 7 July 2020

\begin{abstract}
Background: The use of wedge inferior pubectomy can be challenging to many urethral surgeons. Our objective was to introduce a bone-nibbling technique to accomplish a partial inferior pubectomy (PIP) in a resource-poor setting, and to report the medium- to longterm outcome of using the technique. Methods: Five patients were recruited (mean age: 38.8 years) who presented, over a 30-month period, with posterior urethral fibrosis from a pelvic fracture urethral injury (PFUI). One had failed a previous attempt at posterior urethral reconstruction elsewhere. The length of urethral defect was from 2 to $4 \mathrm{~cm}$. We describe a bone-nibbling technique used to carry out PIP for the delayed repair of PFUI in these patients. The outcomes in the medium to long term of surgical procedures done with this technique are presented. Results: Immediate postoperative complications in all were essentially a Clavien-Dindo grade I. Peak flow rate
\end{abstract}

assessed 12 weeks' post operation was between $20 \mathrm{~mL} / \mathrm{s}$ and $23 \mathrm{~mL} / \mathrm{s}$ (mean: $21 \mathrm{~mL} / \mathrm{s}$ ). The longest duration of follow-up was 34 months, and all patients were voiding satisfactorily. Conclusions: A satisfactory and durable outcome can be obtained from nibbling at the bone from the inferior margin of the pubic bone to achieve PIP. This is of interest to lower urinary tract reconstructive surgeons who have concerns with chiseling-out wedge of the inferior pubis.

Keywords: Bone nibbling, Partial inferior pubectomy, PFUI, Posterior urethra, Urethral anastomosis

Ann Afr Surg. 2021; 18(2): 69-74

DOI: http://dx.doi.org/10.4314/aas.v18i2.2

Conflicts of Interest: None

Funding: None

(C) 2021 Author. This work is licensed under the Creative Commons Attribution 4.0 International License.

\section{Introduction}

Generally, the management of pelvic fracture urethral injury (PFUI) continues to evolve but has remained a challenge. Short-term and long-term outcomes of its management have much improved in the last 2 decades (1). While some surgeons practice early realignment, others prefer delayed reconstruction of the stricture that develops with the healing of the injury (2).

Both groups report acceptable outcomes (3). Repairing the stricture after the PFUI has healed can be challenging
(4), and in the hands of a less experienced surgeon the outcome of such repair may be disappointing. Among the factors contributing to the poor outcome of repair is poor access to the site of surgery due to the rigid configuration of the bony pelvis (5). The unyielding bony pelvis limits access to the proximal healthy urethral segment, increases the chances of incomplete excision of the fibrotic urethral segment, which compromises the integrity of urethral anastomosis, and impairs a successful tension-free anastomosis (6). 
Over the years, various maneuvers have been incorporated into the operative procedure with the primary objectives of improving access to the surgical site and shortening the gap to be breached after the complete excision of the fibrotic segment in a singlestage procedure (7). These maneuvers include splitting the corpora cavernosa in the midline, partially resecting the inferior aspect of the body of the pubic bone (partial inferior pubectomy, PIP), and supracrural rerouting of the urethra $(7,8)$. Use of any or some of these maneuvers has been reported to improve significantly the outcome of such repairs $(8,9)$. Therefore, when indicated, one or more of these maneuvers are frequently used by experienced surgeons $(10,11)$.

A technique for PIP in the delayed repair of PFUI is described (12,13). Many surgeons, irrespective of how long they have been practicing, may have never used this maneuver because of the fear of uncontrollable hemorrhage and concerns about inadvertent injury to other surrounding structures. Nibbling at the pubic bone from the inferior margin may offer the same surgical value as chiseling out a mass of bone. The controlled use of the bone nibbler may increase a surgeon's confidence in their ability to use the technique without collateral damage.

The study aims to describe the bone-nibbling technique of accomplishing a PIP and to give the outcome of its use in our center so far.

\section{Methods}

Medical records were retrieved of five male patients who underwent delayed repair of the PFUI between March 2017 and December 2019usingthe bone-nibbling technique to accomplish PIP. These records were used to audit the outcome. Four of these procedures were primary repairs while one was a repeat repair. The mean age of these men was $38.8 \pm 7.0$ years, and the length of the urethral defect was from 2 to $5 \mathrm{~cm}$. From the records, we reviewed the operating time, need for intraoperation blood transfusion, immediate post operation complications, need for re-establishing a urinary catheter, and urine peak flow rate 3 months post operation.
In addition, institutional records from April 2008 to January 2016 of delayed repair of a PFUI in men were retrieved. All 20 cases identified were undertaken without using PIP. The men were between 20 and 70 years of age with a mean age of $33.8 \pm 12.2$ years. The median length of a urethral defect was $2.5 \mathrm{~cm}$ (range $1.5-5.0 \mathrm{~cm}$ ). From these records, we determined the outcome of repair in terms of the need to re-establish a suprapubic cystostomy or to perform a repeated urethral dilatation and compared it with the test cohort. The mean age of the patients, mean length of urethral defect, and mean units of blood transfused were compared for the two groups using analysis of variance (ANOVA). Crosstab analysis was used to compare outcomes. The Statistical Package for Social Sciences (SPSS Statistics ver. 21.0; IBM, Armonk, NY, USA) was used for analysis.

Figure 1 highlights the bone-nibbling technique of carrying out a PIP: a combined retrograde urethrogram and a voiding cystogram image of a PFUI requiring repair. Briefly, with this repair technique, patient positioning, skin incision and mobilizing the urethra are as described in other references $(5,12,13)$. The lambda (inverted Y) perineal skin incision gives a better exposure with soft tissue retraction. The urethra is transected just distal to the fibrotic segment, and the distal segment is protected from harm. At this stage, the fibrotic segment is left attached to the proximal stump of the urethra to aide retraction while dissecting the proximal urethral segment. The proximal corporal bodies are carefully parted in the midline and the dorsal vein coursing inferior to the symphysis pubis is ligated and transected (5) (Fig. 1).

With the inferior aspect of the pubic body and adjoining rami visualized, the periosteum is incised and striped using a periosteal elevator. Then the inferior pubis is nibbled using a bone nibbler (Fig. 2) until adequate room is created for maneuvering the needle holder, and the necessary tissue forceps and suction nozzle during anastomosis. The proximal urethral stump is further dissected with the help of an antegrade 


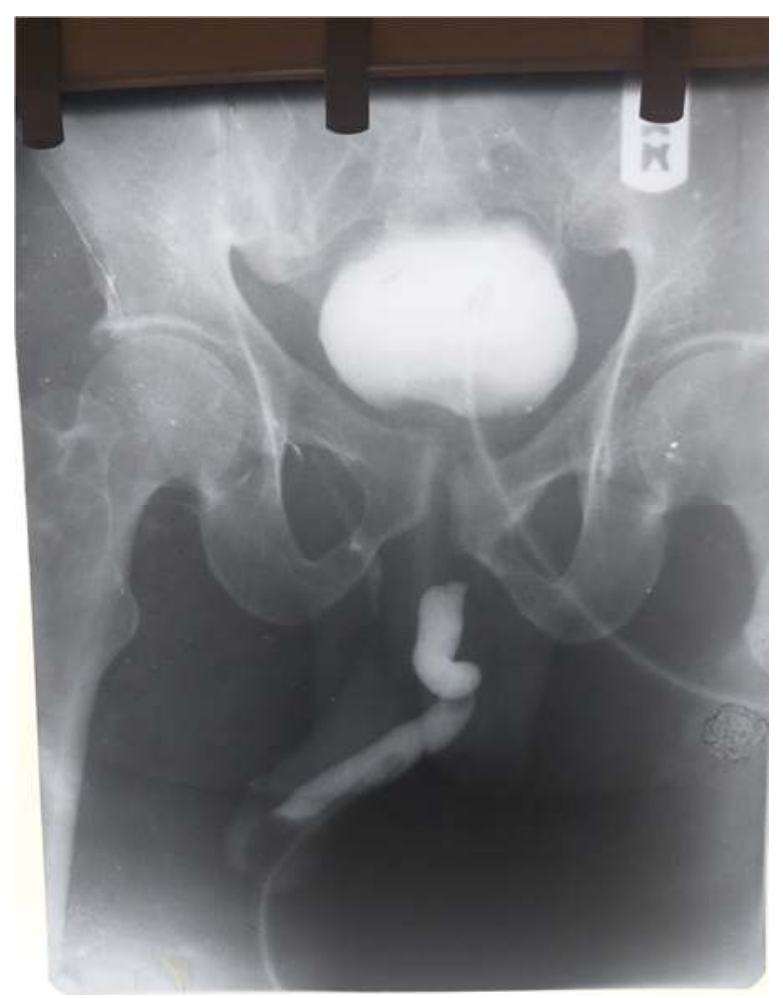

Figure 1. A combined retrograde urethrogram and voiding cystogram image of a PFUI requiring repair

urethral bougie to free enough healthy proximal urethra for anastomosis. Bone wax is applied on the cancellous bone surface for hemostasis. The fibrotic urethral segment is completely excised to expose healthy proximal urethral mucosa (Fig. 3), and a robust end-toend urethral anastomosis is accomplished with relative ease over an appropriately sized urethral catheter. The rest of the procedure is as described elsewhere $(12,13)$. A corrugated wound drain is always left in place for about $48 \mathrm{~h}$, and a firm dressing is placed on the perineum after wound closure. A peri catheter urethrography is done 3 weeks post-surgery and the urethral catheter stent removed thereafter. The post repair peak flowrate was assessed12 weeks post-surgery using uroflowmetry (Figs. 2 and 3).

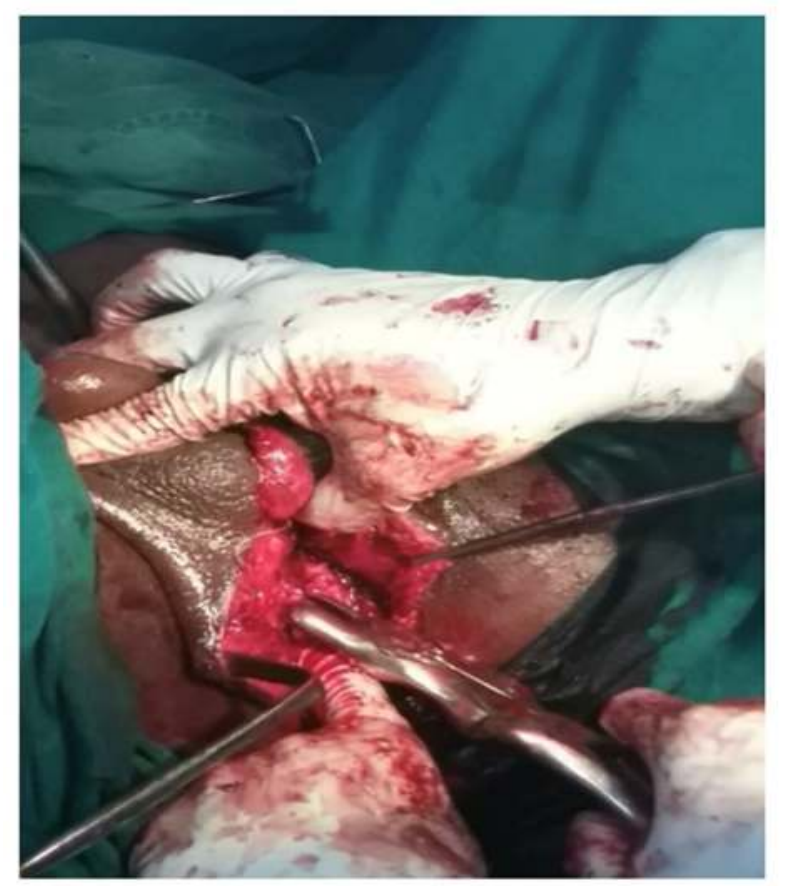

Figure 2. Nibbling at the inferior pubis using a bone nibbler

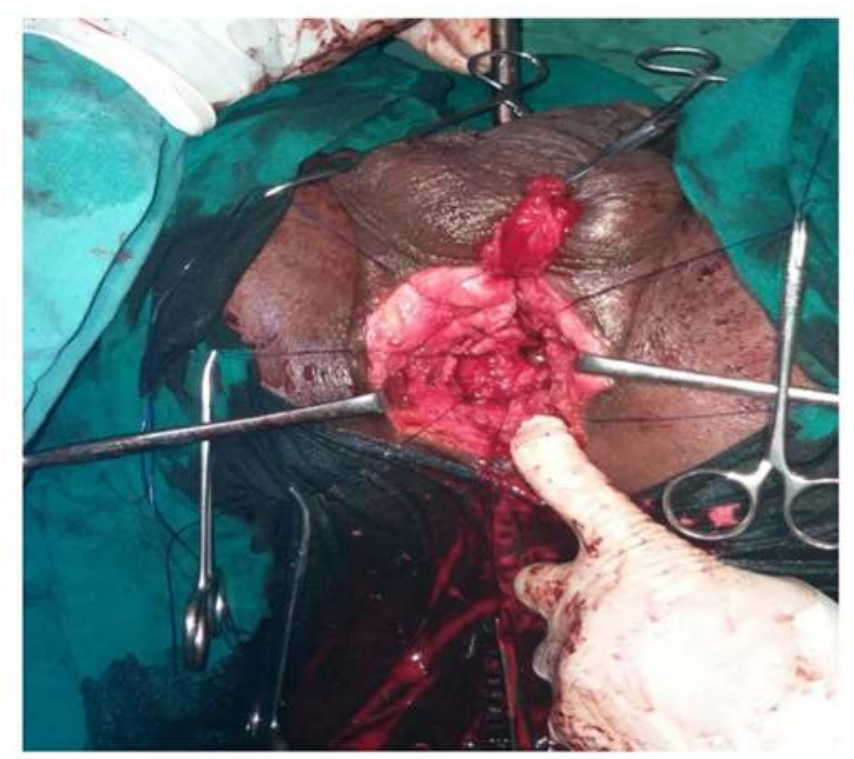

Figure 3. Excision of the fibrotic urethral segment to expose healthy proximal urethral mucosa

\section{Results}

For the PIP cohort, the mean intraoperative blood transfusion rate was $1.4 \pm 0.5$ units per procedure. There was no case of hematoma, deep wound infection, or any complication beyond a Clavien-Dindo grade I (14) 


\begin{tabular}{lllllll}
\hline \multicolumn{6}{l}{ Table 1. Summary of PFUI repairs using bone-nibbling technique of PIP } \\
\hline $\begin{array}{l}\text { Case } \\
\text { Age } \\
(\text { years })\end{array}$ & $\begin{array}{l}\text { LUD transfusion } \\
(\mathrm{cm})\end{array}$ & $\begin{array}{l}\text { Operating } \\
\text { Time } \\
(\mathrm{min})\end{array}$ & $\begin{array}{c}\text { PFR- } \\
\text { months } \\
(\mathrm{mL} / \mathrm{s})\end{array}$ & $\begin{array}{l}\text { Follow-up } \\
\text { period } \\
\text { (months })\end{array}$ \\
\hline 1 & 29 & 3 & 1 & 190 & 23 & 38 \\
2 & 48 & 4 & 2 & 175 & 21 & 34 \\
3 & 39 & 4 & 1 & 150 & 20 & 25 \\
4 & 36 & 2 & 2 & 165 & 20 & 19 \\
5 & 42 & 5 & 1 & 170 & 21 & 18 \\
Mean & $38.8 \pm 7.0$ & $3.6 \pm 1.1$ & $1.4 \pm 0.5$ & $170 \pm 14.6$ & $21 \pm 1.2$ & \\
\hline
\end{tabular}

LUD: Length of urethral defect; PIP: partial inferior pubectomy; PFR: peak flow rate.

in the postoperative period. The post repair peak flowrate had a range of $20-23 \mathrm{~mL} / \mathrm{s}$ with a mean of 21 $\mathrm{mL} / \mathrm{s}$. The longest follow-up period was 34 months and all five patients have maintained satisfactory urine flow to date.

For the non-PIP group, a mean of $1.6 \pm 0.6$ units of whole blood were transfused per surgical procedure. In about $60 \%$ of repairs, there was compelling need to reestablish the use of a suprapubic catheter for micturition or to perform repeated urethral dilatations within 6 months post operation. There was little or no evidence of any significant variations in the age of the patients $(p=0.39)$, length of urethral defect repaired $(p=0.05)$, and in blood transfusion per procedure $(\mathrm{p}=0.50)$ between the two groups. However, there was evidence showing outcome is better in the PIP cohort $(\mathrm{p}=0.02)$ (Table 1$)$.

\section{Discussion}

One of the limitations to ensuring a durable end-to-end anastomosis at the posterior urethra is poor access (5). To overcome this limitation, various specially designed instruments, suture needles, and retractors have been introduced for use during this procedure (15). The struggle to complete this anastomosis in the difficult conditions of poor access increases the risk of poor tissue handling and of performing anastomosis of doubtful integrity, resulting in poor outcome with its attendant burden on the patient, the surgeon, and the health system $(6,16)$. Recurrence of posterior urethral fibrosis requiring further procedures or repeat reconstructions is common (17). With the recognition that the first attempt at repair provides the best chance for a successful outcome, recurrence is worrisome $(17,18)$. Beyond the space constraint, the urethral length constraint (Fig. 1) presents another limitation in accomplishing tension-free, robust end-to-end anastomosis after excising the fibrotic urethral segment (7). The extent of the urethral length challenge understandably depends on the length of the excised urethral segment.

PIP is a maneuver recommended to reasonably overcome both space and urethral length constraints (8). However, many surgeons are not enthusiastic about this maneuver for fear of encountering uncontrollable bleeding or causing damage to other structures by adopting a wedge pubectomy technique using rongeurs $(2,9)$. In a recent yet to be published survey of urologists in Nigeria (19), of the respondents who have witnessed 
wedge PIP in the delayed repair of PFUI, $70.6 \%$ are yet to use this technique due to concerns of primary hemorrhage and $64.7 \%$ are concerned about damage to other structures.

PFUI appears to be a generally uncommon limiting experience with its management beyond the initial diversion of urine (20,21). Reports from our local and regional settings show that the outcome of surgery for PFUI repair is generally not as good as the outcome of repair of an anterior urethral stricture (22). This may be because these PFUI repairs are done without performing PIP, thereby undertaking urethral anastomosis in the very challenging circumstances of the surgical field and urethral length constraints. Undertaking such urethral anastomosis in the context of space and length constraints will generally lead to suboptimal repair outcome.

The bone-nibbling technique described here (Fig. 2) offers an alternative to achieving the same goals of improving on surgical access and urethral length constraints. At the same time, it may reduce the concern of inadvertent damage to tissue. The controlled engagement and cutting using the bone nibbler repeatedly from the inferior margin of the pubis may be easier to appreciate and incorporate into surgical practice than the conventional wedge pubectomy. Nibbling at the pubic bone does not appear to increase primary hemorrhage. This study reveals that the blood transfusion rate is not increased as a result of using this technique to perform PIP. To the benefit of both surgeon and patient, adequate surgical space is created for robust primary urethral anastomosis (Fig. 3) with improved chances of a good and durable outcome (Table 1).

Unarguably, use of the PIP maneuver in surgeries for PFUI repair generally increases the chances of good surgical outcomes $(10,23,24)$. Urethral reconstructive surgeons who may have concerns about chiseling out a mass of pubic bone to carry out a wedge inferior partial pubectomy could nibble at the bone from the inferior margin instead of undertaking the urethral anastomosis, without PIP, in less-than-optimal conditions with the attendant poor repair outcome.

\section{Conclusion}

We recommend the use of PIP to repair PFUI-related urethral fibrosis in order to overcome constraints in surgical access and healthy urethral length during urethral anastomosis. To accomplish PIP, the pubic bone can be nibbled at from the inferior margin where wedge inferior pubectomy cannot be conveniently put to use. Medium- and long-term outcomes show that nibbling at the inferior margin of pubic bone does not further increase the risk of PIP, and offers durable repair outcome.

\section{Acknowledgment}

The authors acknowledge the assistance of Nweze Ekwuribe in the production of this manuscript.

\section{References}

1. Dugi DD, Simhan J, Morey AF. Urethroplasty for stricture disease: contemporary techniques and outcomes. Urology. 2016; 89:12-18.

2. Joshi PM, Batra V, Kulkarni SB. Controversies in the management of pelvic fracture urethral distraction defects. Turk J Urol. 2019; 45:1-6.

3. Zou Q, Zhou S, Zhang K, et al. The immediate management of pelvic fracture urethral injury Endoscopic realignment or cystostomy? J Urol. 2017; 198:869-874.

4. Gomez RG, Scarberry K. Anatomy and techniques in posterior urethroplasty. Transl Androl Urol. 2018; 7:567579

5. Gelman J, Wisenbaugh ES. Posterior urethral strictures. Adv Urol. 2015:628107.

6. Koraitim MM. Optimizing the outcome after anastomotic posterior urethroplasty. Arab J Urol. 2015; 13:27-31.

7. Koraitim MM. Trans pubic urethroplasty revisited: total, superior, or inferior pubectomy? Urology. 2010; 75:691694.

8. Singh SK, Pawar DS, Khandelwal AK, et al. Trans perineal bulboprostatic anastomotic repair of pelvic fracture urethral distraction defect and role of ancillary maneuver: A retrospective study in 172 patients. Urol Ann. 2010; 2:53-57.

9. Webster GD, Peterson AC. Simple perineal and elaborated perineal posterior urethroplasty. Arab J Urol. 2015; 13:1723.

10. Kulkarni SB, Barbagli G, Kulkarni JS, et al. Posterior urethral stricture after pelvic fracture urethral distraction defects in developing and developed countries, and choice of surgical technique. J Urol. 2010; 183:1049-1054. 
11. Trachta J, Moravek J, Kriz J, et al. Pediatric bulbar and posterior urethral injuries: operative outcomes and longterm follow-up. Eur J Pediatr Surg. 2016; 26:86-90.

12. Manikandan R, Dorairajan LN, Kumar S. Current concepts in the management of pelvic fracture urethral distraction defects. Indian J Urol. 2011; 27:385-391.

13. Morey AF, McAninch JW. Reconstruction of posterior urethral disruption injuries: Outcome analysis in 82 patients. J Urol. 1997; 157:506-510.

14. Mamoulakis C, Efthimiou I, Kazoulis S, et al. The modified Clavien classification system: a standardized platform for reporting complications in transurethral resection of the prostate. World J Urol. 2011; 29:205-210.

15. Barbagli G, Kulkarni SB, Joshi PM, et al. Repair of sphincter urethral strictures preserving urinary continence: surgical technique and outcomes. World J Urol. 2019; 37:2473-2479.

16. Garg G, Singh M, Kumar M, et al. Outcome of patients with failed pelvic fracture-associated urethral injury repair: a single center 10-year experience. Turk J Urol. 2018; 45:139-145.

17. Sunay M, Karabulut A, Dadali M, et al. Single-institution outcomes of open reconstruction techniques for management of pediatric and adolescent post-traumatic urethral strictures. Urology. 2011; 77:706-710.

18. Helmy TE, Sarhan O, Hafez AT, et al. Perineal anastomotic urethroplasty in a pediatriccohort with posterior urethral strictures: critical analysis of outcomes in a contemporary series. Urology. 2014; 83:1145-1148.

19. Nnabugwu, I. Deployment of partial inferior pubectomy by urologists in Nigeria. Unpublished Mendeley Data. 2019. V1 http://dx.doi.org/10.17632/d63cdgz6td.1

20. Andrich DE, Greenwell TJ, Mundy AR. Treatment of pelvic fracture-related urethral trauma: a survey of current practice in the UK. Br J Urol. Int. 2005; 96:127-130.

21. Wong NC, Allard CB, Dason S, et al. Management of pelvic fracture-associated urethral injuries: a survey of Canadian urologists. Can Urol Assoc J. 2017;11: E74-E78.

22. Obi AO. Short segment bulbar urethral strictures: review of 48 cases managed in a resource-poor setting. Niger $\mathbf{J}$ Clin Pract. 2017; 20:1020-1026.

23. $\mathrm{Fu} \mathrm{Q}, \mathrm{Xu} \mathrm{YM}$, Zhang J, et al. Use of anastomotic urethroplasty with partial pubectomy for posterior urethral obliteration injuries: 10-year experience. World J Urol. 2009; 27:695-699.

24. Horiguchi A, Edo H, Soga S, et al. Pubourethral stump angle measured on preoperative Magnetic Resonance Imaging predicts urethroplasty type for pelvic fracture urethral injury repair. Urology. 2018; 112:198-204. 